\title{
CHI PHÍ Y TẾ TRỰC TIẾP TRONG ĐIỀU TRI HEN THEO PHÂN LOAI GINA DỰA TRÊN PHÂN TÍCH DỮ LIỆU LỚN TỪ BẢO HIỂM Y TẾ VIÊTT NAM NĂM 2019
}

\author{
Phạm Huy Tuấn Kiệt ${ }^{1}$, Vũ Văn Giáp ${ }^{1}$, Nguyễn Thị Thanh Hà
}

TÓM TẮT

Mục tiêu: Khảo sát chi phí điều trị bênh hen (suyển) theo quan điểm người chi trả dựa trên phân tích dữ liệu thực tế từ Bảo hiểm Y tế năm 2019. Đối tượng và phướng pháp nghiên cứu: Nghiên cứu mô tả cắt ngang được thực hiện để đánh giá chi phí y tế trực tiếp của người bểnh hen theo phân loại mức đô nẳng dựa trên GINA (Global Initiative for Asthma) và theo tình trạng cơn kịch phát. Kết quả: Chi phí trung bình của người bệnh hen bậc $1,2,3-4$ và 5 lần lượt là $1.166 .757,3.222 .625,4.671 .554$ và 9.229.319 đồng. Chi phí thuốc chiếm tí trong chủ yếu trong chi phí điều trị bệnh hen. So với người bệnh không có đợt kịch phát, người bệnh có đợt kịch phát nhẹ-trung bình và người bệnh có đợt kịch phát nặng làm chi phí tăng lần lượt gẩp 3 và 4,5 lần. Kết luận: Các giải pháp nhằm kiểm soát bệnh hen tốt hơn và làm giảm sự xuất hiện của các cợn kịch phát có ý nghĩa quan trọng trong việc giảm gánh nặng bệnh tật do bệnh hen gây ra.

Tư khóa: Chi phí y tế trực tiếp, Bảo hiểm y tế, Gánh nặng bệnh tật, Hen

\section{SUMMARY}

\section{DIRECT MEDICAL COST OF ASTHMA MANAGEMENT IN VIETNAM FOLLOWING CLASSIFCATION OF GINA BASED ON BIG DATA ANALYSIS OF NATIONAL HEALTH INSURANCE DATABASE IN 2019}

Objective: To evaluate the direct medical cost of asthma management from the perspective of payer based on big data analysis of national health insurance database in 2019. Methods: A descriptive cross-sectional study was conducted to calculate direct medical cost of asthma patients classified by GINA (Global Initiative for Asthma) and by severity of exacerbation. Results: Average cost of patients in GINA step 1, 2, 3-4 and 5 was 1,166,757, 3,222,625, $4,671,554$ and $9,229,319$, respectively. Medication cost accounted for a significant proportion in the cost of treatment. Compared to patients without exacerbations, those with mild-moderate exacerbations and those with severe exacerbation had 3 times and 5 times higher cost, respectively. Conclusion: Measures that improve asthma control

${ }^{1}$ Trường Đại học Y Hà Nội

²Ban Thực hiện chính sách bảo hiểm y tê, Bảo hiểm Xã hội Viêt Nam

Chịu trách nhiệm chính: Phạm Huy Tuấn Kiệt

Email: phamhuytuankiet@gmail.com

Ngày nhận bài: 12.4 .2021

Ngày phản biện khoa học: 26.5.2021

Ngày duyệt bài: 11.6.2021 and reduce occurrence of exacerbations can decrease the economic burden of asthma.

Keywords: Direct medical cost, Health insurance, Burden of disease, Asthma

\section{I. ĐĂT VẤN ĐỀ}

Hen (suyễn) là bệnh lý được đặc trưng bởi tình trạng viêm mạn tính đường thờ, co thắt cơ trơn phế quản khi có các tác nhân kích thích gây ra các triệu chứng hô hấp: ho, khó thở, khò khè, nặng ngực,... Trong những thập kỉ gân đây, ngoài các yếu tố liên quan đến di truyên, lối sống hiện đại hóa đang làm tăng dân tỉ lệ hiện mắc và mới mắc của hen trên toàn thế giới [1]. Ở Việt Nam, số người bệnh hen đã tăng lên đáng kể, theo nghiên cứu của Dương Quý Sỹ và cộng sự tại Đà Lạt, tỉ lệ hiện mắc bệnh hen là 2\% ở những người trưởng thành vào năm 2004 [2].

Một số nghiên cứu trên thế giới và tại Việt Nam cho thấy gánh nặng chi phí gia tăng theo mức độ nặng. Nghiên cứu năm 2020 ở Mỹ chỉ ra rằng chi phí điều trị hen theo mức độ nhẹ, trung bình, nặng là $3.305,7.250$ và 9.175 đồ la Mỹ $(p<0.05)$ [3]. Nghiên cứu cửa các tác giả Nguyễn Thị Thu Thủy và Nguyễn Ngọc Bảo Thi tại Việt Nam vào năm 2016 ước tính tổng gánh nặng kinh tế theo các mức độ nặng của bệnh hen lần lượt là 4,9, 10,7 và 13,2 triệu đồng theo quan điểm người chi trả [4]. Ngoài ra, việc không kiểm soát tốt bệnh hen cũng là gia tăng về mặt chi phí điều trị. Đã có các bằng chứng khoa học cho thấy người bệnh có xuất hiện cơn hơn cấp chi trả nhiều hơn đáng kể so với nhóm còn lại [5].

Hiện tại, các nghiên cứu tại Việt Nam ước tính chi phí dựa trên mô hình hoặc khảo sát một quân thể dân số, còn ít các nghiên cứu thực hiện trên dữ liệu quốc gia $[4,6]$. Đồng thời, thông tin về chi phí điêuu trị đối với người bệnh có cơn hen cấp còn hạn chế. Đứng trước thực trạng đó, đề tài này được tiến hành nhằm đánh giá chi phí y tế trực tiếp do bệnh hen theo mức độ nặng và tình trạng cơn hen cấp dưới góc độ người chi trả, dựa trên dữ liệu thực tế từ Bảo hiểm $Y$ tế năm 2019.

II. ĐỐI TƯợNG VÀ PHƯƠNG PHÁP NGHIÊN CỨU

Đôi tượng nghiên cứu. Chi phí y tế trực tiếp trong điều trị hen năm 2019 theo quan điểm người 
chi trả từ dữ liệu Bảo hiểm Xã hôi Viê̂t Nam.

Phương pháp nghiên cứu. Nghiên cứu mô tả cắt ngang hồi cứu được thực hiện dựa vào hồ sơ của các lượt khám bểnh của các bểnh nhân. Dữ liêu được trích xuất từ cơ sở dữ liêu thanh toán bảo hiểm y tế của Bảo hiểm Xã hội Việt Nam năm 2019.

Tiêu chí lựa chọn và loại trừ. Nghiên cứu lựa chọn những hồ sơ của các lượt khám bệnh có mã ICD-10 (International Classification of Diseases 10th Edition) là 345 (hen) và $J 46$ (cơn hen ác tính) trong năm 2019. Tiêu chí loai trừ gồm những hồ sơ của các lượt khám không cung cấp đầy đủ dữ liệu để phân tích và những hồ sơ của người bệnh không thể phân loại theo GINA (Global Initiative for Asthma) dựa trền dữ liệu hệ thống được trình bày bên dưới.

Phân loại mức độ hen theo bậc của GINA. Người bệnh được phân loại theo GINA 2018 [7] dựa trên loại thuốc được sử dụng trong dữ liệu hệ thống, cụ thể như sau:

- Hen bậc 1: SABA khi cần;

- Hen bậc 2: sử dụng ICS và SABA khi cần

- Hen bâc 3-4: sử dung ICS phối hợp với LABA và $S A B A$ khi cần

- Hen bậc 5: điều trị như hen bậc 3-4 có sử dụng thêm các thuốc thuộc nhóm LAMA,

\section{KẾT QUẢ NGHIÊN CỨU}

Bảng 1. Đặc điểm người bệnh hen theo phân loại GINA

\begin{tabular}{|c|c|c|c|c|}
\hline & Hen bậc 1 & Hen bậc 2 & Hen bậc 3-4 & Hen bậc 5 \\
\hline Số bệnh nhân(N) & 15.852 & 4.434 & 19.259 & 32.442 \\
\hline Tuối & & & & \\
\hline Trung bình (Độ lệch chuấn) & $35,1(29,1)$ & $27,2(28,8)$ & $56,4(18,5)$ & $53,1(19,0)$ \\
\hline$<12$ & $37,8 \%$ & $52,2 \%$ & $2,1 \%$ & $3,6 \%$ \\
\hline $12-<18$ & $2,6 \%$ & $2,4 \%$ & $1,4 \%$ & $1,9 \%$ \\
\hline $18-<44$ & $17,1 \%$ & $14,2 \%$ & $20,4 \%$ & $23,7 \%$ \\
\hline $45-<64$ & $21,9 \%$ & $15,1 \%$ & $40,2 \%$ & $41,9 \%$ \\
\hline $65-<74$ & $10,8 \%$ & $8,5 \%$ & $20,6 \%$ & $17,4 \%$ \\
\hline$<75$ & $9,8 \%$ & $7,6 \%$ & $15,3 \%$ & $11,5 \%$ \\
\hline Nam & $51,3 \%$ & $52,6 \%$ & $54,7 \%$ & $49,7 \%$ \\
\hline Giới tính: & $48,7 \%$ & $47,4 \%$ & $45,3 \%$ & $50,3 \%$ \\
\hline Số lượt khám bệnh & & & & \\
\hline Trung bình (Độ lệch chuấn) & $1,3(1,2)$ & $1,4(1,3)$ & $3,9(5,1)$ & $6,3(6,5)$ \\
\hline Số ngày năm viện & & & & \\
\hline Trung bình (Độ lệch chuấn) & $1,7(4,2)$ & $5,1(7,5)$ & $1,1(5,9)$ & $5,3(12,3)$ \\
\hline Các bệnh đồng măc & & & & \\
\hline Rối loạn lo âu lan tỏa & $4,1 \%$ & $3,2 \%$ & $8,4 \%$ & $22,1 \%$ \\
\hline Viêm mû̃i & $<0,0 \%$ & $<0,0 \%$ & $0,1 \%$ & $<0,0 \%$ \\
\hline Viêm xoang & $5,6 \%$ & $3,1 \%$ & $1,7 \%$ & $6,2 \%$ \\
\hline Polyp mũi & $2,5 \%$ & $2,8 \%$ & $2,0 \%$ & $5,3 \%$ \\
\hline
\end{tabular}

Có 71,987 người bệnh được phân tích trong nghiên cứu thỏa mãn các tiêu chuẩn lựa chọn và tiêu chuẩn loại trừ được xác định trước đó. Bảng 1 trình bày kết quả người bệnh hen trong nghiên corticoid đường uống và đối kháng thụ thể Leukotriene

Những bệnh nhân không thỏa được các điều kiện trên sẽ được xếp vào nhóm hen khác.

Cơn hen cấp được xác định dựa vào mã ICD$10 J 46$ và được phân loại mức độ nặng như sau:

- Cơn hen kịch phát nhẹ-trung bình: (1) nhập việ/cấp cứu; (2) có sử dụng thuốc cắt cợn SABA; SAMA (3) có hoặc không sử dụng corticoid đường uống; và (4) Không phải thở oxy

- Cơn hen kịch phát năng: (1) nhập viện/cấp cứu; (2) có sử dụng thuốc cắt cớn SABA; SAMA (3) có hoặc khổng sử dụng corticoid đường

Xử lý số liệu. Phương pháp thống kê mô tả được sử dung để ước tính chi phí y tế trực tiếp trong điêu trị hen theo các bậc phân loại của GINA và mức độ nặng của cởn hen cấp bằng phần mềm Microsoft Excel 2016 và SPSS 20.0. Chi phí được quy đổi về năm 2020 theo công thức

Chi phí $2020=$ Chi phí 2019 x CPI2020/CPI 2019

Với CPI (Consumer Price Index) là chỉ số giá tiêu dùng của tất cả hàng hóa và y tế được ước tính bởi Tổng Cục Thống kê Việt Nam.

\begin{tabular}{|c|c|c|}
\hline Năm & 2019 & 2020 \\
\hline CPI & 100,0 & 102,2 \\
\hline
\end{tabular}
uống; và (4) có phải thở oxy hoặc thở máy. cứu phân loại theo GINA. Tỉ lệ người bênh hen bậc 5 chiếm trọng số cao nhất $(45,1 \%)$, sau đó là số người bệnh hen bậc 3-4 (26,8\%). Độ tuổi trung bình của nhóm người bệnh hen bậc cao 
cao hơn so với nhóm người bệnh bậc thấp. Tỉ lệ giới tính nam nữ phân bố đồng đều giữa các nhóm người bệnh hen. Số lượt khám bệnh tăng dần theo bậc hen GINA từ 1 đến 5 (từ 1,3 lần đến 6,5 lần). Số ngày nằm viện trung bình cao nhất ở nhóm người bệnh hen bậc 2 và thấp nhất ở nhóm người bệnh hen bậc 3-4. Tỷ lệ đồng mắc viêm mũi hầu như không có sự khác biệt ở các nhóm người bệnh và gần bằng $0 \%$. Bệnh rối loạn lo âu lan tỏa có tỉ lệ cao nhất trong các bệnh quan tâm với gần $1 / 4$ số người bệnh hen bậc 5 mắc hội chứng rối loạn lo âu lan tỏa.
Tổng gánh năng ước tính trên toàn dân số là 422.171.583.334 VNĐ với chi phí điều trị trung bình trên một người bệnh là $5,864,553$ VNĐ. Bảng 2 trình bày chi phí điều trị bệnh hen theo phân loai GINA. Chi phí trung bình của người bệnh hen bậc 1,2 , 3-4 và 5 lần lượt là 1.166.757, 3.222.625, 4.671.554 và 9.229.319 đồng. Tổng gánh nặng chi phí ở các bậc 1, 2, 3-4 và 5 lần lượt là $\quad 18.495 .429 .696, \quad 14.289 .120 .027$, 89.969.453.332 và 299.417.580.280 đồng, trong đó chi phí do bảo hiểm chi trả chiếm khoảng $90 \%$ tổng chi phí của bệnh.

Bảng 2. Chi phí điều trị bệnh hen theo phân loại GINA

\begin{tabular}{|c|c|c|c|c|}
\hline & Hen bậc 1 & Hen bậc 2 & Hen bậc 3-4 & Hen bậc 5 \\
\hline Trung bình & 1.166 .757 & 3.222 .625 & 4.671 .554 & 9.229 .319 \\
\hline Trung vị & 280.013 & 1.676 .733 & 1.181 .837 & 2.846 .842 \\
\hline Độ lệch chuấn & 3.122 .558 & 4.356 .406 & 4.199 .060 & 9.367 .551 \\
\hline Tồng chi phí & 18.495 .429 .696 & 14.289 .120 .027 & 89.969 .453 .332 & 299.417 .580 .280 \\
\hline Tống chi phí do bảo hiếm chi trả & 17.205 .699 .596 & 12.811 .559 .214 & 80.766 .006 .989 & 266.528 .888 .295 \\
\hline Tống chi phí người bệnh đồng chi trả & 962.801 .340 & 778.895 .247 & 8.732 .862 .952 & 30.394 .322 .216 \\
\hline
\end{tabular}

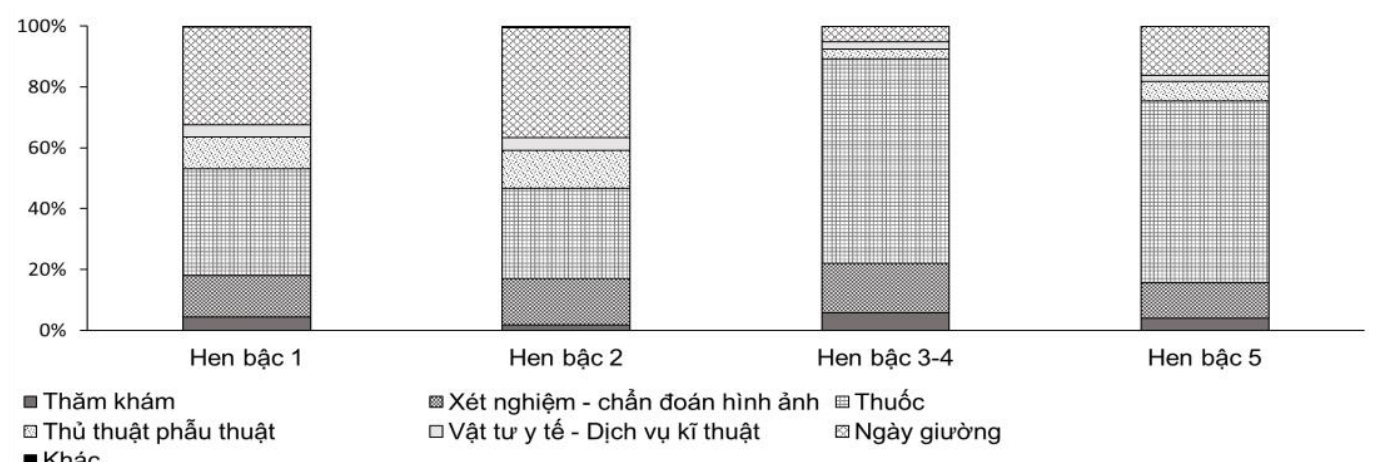

Hình 1. Phân bổ chi phí điều trị hen theo phân loại GINA

Phân bổ chi phí cho các nguồn lực y tế sử dụng điều trị hen các bâc theo phân loại GINA được thể hiện ở Hình 1. Ở người bênh hen bậc 1 và bậc 2 , phân bổ chi phí có sư tưởng đồng giữa các nguồn lực khác nhau được sử dụng. Ở người bênh hen bậc 1 và bậc 2, hai loại hình chi phí chiếm tỉ trong lớn nhất là chi phí thuốc và chi phí ngày giường. Ở người bênh hen bâc $3-4$ và 5 , chi phí thuốc chiếm tỉ trọng đáng kể (trên $60 \%$ ) so với các loại dịch vụ khác.

Sư chênh lệch trong chi phí điều tri của bênh hen theo tình trang cơn hen kịch phát được thể hiện ở Hình 2. Chi phí trung bình của người bệnh hen tăng dần theo mức độ trầm trọng của các đợt kịch phát. So với người bệnh không có cơn kịch phát, chi phí điều trị trung bình của người bênh có cơn kịch phát nặng cao hơn gấp 4,5 lần và chi phí điều trị trung bình của người bệnh có cơn kịch phát nhẹ-trung bình cao hơn gấp 3 lần.

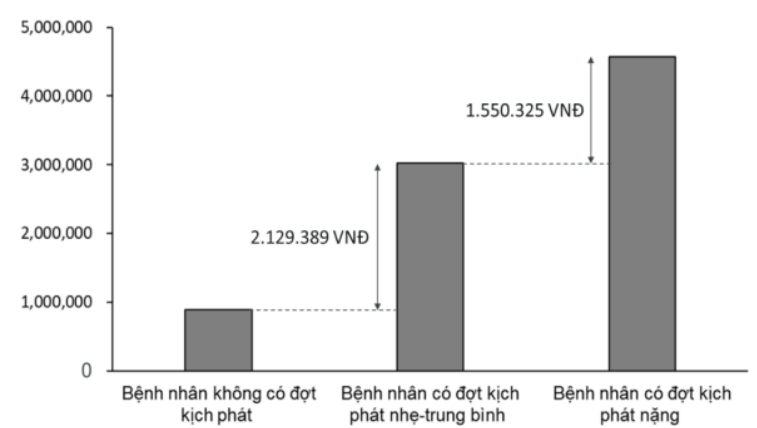

Hình 2. Chi phí điều trị trung bình của người bệnh không có đợt câp, có đợt câp nhe - trung IV. BÀN LUÂ̂N binh và đợt cấp nặng

Chi phí y tế trực tiếp trung bình của người bệnh hen bậc 1, 2, 3-4 và 5 lần lượt là $1.166 .757,3.222 .625,4.671 .554$ và 9.229 .319 đồng. Từ đó cho thấy gánh nặng chi phí tăng dần theo mức độ bệnh. Điều này tương đồng với 
một nghiên cứu khác tại Việt Nam với chi phí y tế trực tiếp hằng năm của nhóm bệnh nhân hen nhẹ, trung bình và nặng được ước tính lần lượt là 6.548.156 đồng, 8.829.234 đồng và 10.746.280 đồng [4].

Chi phí của người bệnh có cơn kịch phát nặng cao hơn khoảng 2,1 triệu và chi phí của người bệnh có cơn kịch phát nhẹ-trung bình cao hơn khoảng 3,6 triệu so với người bệnh không có xuất hiện cơn kịch phát. Một nghiên cứu tại Mỹ cũng cho thây chi phí điều trị của người bệnh có cơn kịch phát gấp đôi so với người không có cơn kịch phát [5]. Qua đó nhấn mạnh các đợt kịch phát làm gia tăng một lượng lớn chi phí và gánh nặng cho người bệnh hen.

Nghiên cứu phân tích dữ liêu lớn với 71,987 người bệnh và 306,338 lượt khám bệnh. Mặc dù còn một số điểm hạn chế (không trực tiếp lấy được các thông tin đầy đủ của bệnh nhân, viêc kê đơn thuốc đôi khi còn phụ thuộc vào sự sẵn có cuả thuốc bảo hiểm y tế tại thời điểm bệnh nhân đi khám bệnh,...), tuy nhiên đề tài này đáp ứng được nhu cầu cập nhật tình hình bênh hen hiện tại và đảm bảo được dữ liệu mang tính thực tế. Các kết quả của nghiên cứu này làm nổi lền một vấn đề đáng lưu tâm. Việc không kiểm soát tốt bệnh hen sẽ làm tăng đáng kể gánh nặng chi trả dịch vụ y tế trong điều trị hen. Các biên pháp, chính sách can thiệp hợp lý nhằm tối thiểu hóa chi phí điều trị cho bệnh nhân và tăng cường kiểm soát hen sẽ góp phần giảm chi phí điêuu trị hen trong tương lai.

\section{KẾT LUÂNN}

Chi phí y tế trực tiếp trong điều trị bệnh hen tăng dần theo mức độ nặng của bệnh và mức độ nặng của cơn hen kịch phát. Chi phí điêuu trị trung bình của người bệnh có cơn hen kịch phát cao hơn gấp 3-4,5 lần chi phí điều trị của người bênh không có cơn hen kịch phát. Từ đó cho thấy, việc tăng cường kiểm soát hen là một giải pháp tiềm năng trong việc giảm gánh nặng kinh tế của bệnh hen lên quỹ bảo hiểm của Việt Nam.

LỜI CẢM ƠN. Cảm ơn Công ty Astrazeneca Việt Nam đã hỗ trợ kinh phí vì mục đích giảm gánh nặng điêu trị bệnh hen tại Việt Nam. Astrazeneca Việt Nam không can thiệp vào quá trình thu thập, phân tích số liệu cũng như báo cáo kết quả của nghiên cứu này.

\section{TÀI LIÊU THAM KHẢO}

1. Nunes, C., Pereira, A.M., and MoraisAlmeida, M., Asthma costs and social impact. Asthma Res Pract 2017; 3: p. 1.

2. Sy, D., et al., Prevalence of asthma and asthmalike symptoms in Dalat Highlands, Vietnam. Singapore Med J. 2007; 48(4): p. 10.

3. Song, H.J., et al., Medical Costs and Productivity Loss Due to Mild, Moderate, and Severe Asthma in the United States. J Asthma Allergy 2020; 13: p. 545-555.

4. Nguyen, T.T.T. and Nguyen, N.B.T., Cost of Asthma in Vietnam. Value in Health 2014; 17: p. A174.

5. Hamdi, B., et al., Estimation of the hospitalization cost for asthma exacerbation in a pulmonology department. 2017; 50(suppl 61): p. PA3568.

6. Le, N.Q., et al., The economic impact of asthma treatment on patients, 2014-2017: The Vietnamese experience from a public hospital. J Pak Med Assoc 2019; 69(Suppl 2)(6): p. S2-s9.

7. Global Initiative for Asthma (GINA), Pocket Guide for Health Professionals Updated 2019. 2019.

\section{HIỆU QUẢ CỦA KIT TROPOCELLA TRONG ĐIỀU TRI VIÊM LỒI CẦU NGOÀI XƯO'NG CÁNH TAY}

\section{TÓM TẮT}

Mục tiêu: Đánh giá kết quả điều trị viêm lồi câu ngoài xương cánh tay bằng liệu pháp huyết tương giàu tiểu cầu bằng kit Tropocell và khảo sát tác dụng không mong muốn của liệu pháp sau 12 tuần theo

\footnotetext{
${ }^{1}$ Trường Cao đẳng y tế Thái Bình

${ }^{2}$ Bệnh viện Đại học Y Hà Nội

${ }^{3}$ Trường Đai hoc Y Hà Nôii

Chịu trách nhiệm chính: Đinh Ánh Mai

Email: anhmaiytb@gmail.com

Ngày nhận bài: 8.4.2021

Ngày phản biên khoa hoc: 24.5.2021

Ngày duyệt bài: 8.6 .2021
}

Đinh Ánh Mai ${ }^{1}$, Phạm Hoài Thu ${ }^{2,3}$

dõi. Đối tượng và phương pháp: Nghiên cứu can thiệp có đối chứng theo dỗi trong 12 tuân trên 47 bệnh nhân viêm lồi cầu ngoài xương cánh tay được chia làm 2 nhóm: 24 bênh nhân được tiêm tại chỗ huyết tương giàu tiểu cầu bằng Kit Tropocell 3 mũi cách nhau mối 3 tuần, 23 bênh nhân được tiêm tại chỗ Depo - Medrol một lần duy nhất. Kết quả: Sau 12 tuần điều trị, các triêu chứng lâm sàng đều có cải thiện ở nhóm nghiên cứu: điểm VAS trung bình giảm từ 7.17 xuống 1.42, điểm Q-DASH trung bình giảm từ 74.15 xuống 28.44, điểm PRTEE trung bình giảm từ 59.35 xuống $13.75,(p<0.05)$. Có $12.5 \%$ trường hợp đau tăng tại vị trí tiêm ở nhóm tiêm huyết tương giàu tiểu câu, $17.4 \%$ ở nhóm tiêm Depo - Medrol ( $p$ > 0.05) và không gặp các tác dụng không mong muốn 